\title{
Discussion on the Texture Beauty of Yuzhou Daily Jun Porcelain and the Design of Derivatives
}

\author{
Lin Liu ${ }^{1}$, Xinyu $\mathrm{Wu}^{2, *}$ \\ ${ }^{1}$ School of Art and Design of Hubei University of Technology, Wuhan 430068 \\ ${ }^{2}$ School of Art and Design of Hubei University of Technology, Wuhan 430068 \\ ${ }^{*}$ Corresponding author. Email: wxy17838368867@163.com
}

\begin{abstract}
From the blank making to the porcelain which is made through mixing of clay and water, the texture beauty formed on the surface of porcelain is a miracle that can only be found by accident. The texture beauty of Jun Porcelain is an abstract form formed in the process of furnace transmutation. It is the ever-changing texture of the glazing color deduced from the blank making, glaze or firing. The texture beauty of Jun Porcelain in Yuzhou daily is both green and red, which is very aesthetic and contains rich cultural connotation. In this paper, the origin, dominant and invisible texture beauty of Jun Porcelain in Yuzhou are analyzed and discussed, which is helpful for the structure and form of the texture beauty of Jun Porcelain to be skillfully used in the design of derivatives, so that the texture beauty of Jun porcelain can be loved and appreciated by more people.
\end{abstract}

Keywords: Yuzhou Jun Porcelain, Daily Jun Porcelain, Texture Beauty, Design of Derivatives

\section{INTRODUCTION}

Yuzhou Jun porcelain was once a ceremonial vessel in history from the Northern Song Dynasty to the present day, not affected by the change of dynasties. Yuzhou daily-use Jun porcelain has a symbolic significance as a ceremonial vessel with smooth and simple shapes, decorated with and colorful glazes. It is beloved by its exquisite, elegant and divine texture beauty. Jun kiln is made in Yuzhou in the early Song dynasty with fine, solid texture and slightly heavy body. The glaze has five colors with dodder mark, which is deep and dense. Red like carmine or vermilion is the best, followed by lush green and blackish purple[1]. Yuzhou Jun porcelain is famous for its high-temperature "kiln transmutation", which are naturally occurring on the surface of the glaze with a wide variety of texture and glaze colors. Although the color of Jun glaze is purely mixed and uniform, the glaze is thick and lustrous, like a candle flowing into a pile of wax. The visual experience and sensory impression of texture beauty is impressive. As society becomes more aware of environmental protection and porcelain art supplies start to increase, Yuzhou daily-use Jun porcelain is receiving more and more attention as a cultural industry of traditional crafts, as well as the development and design of its derivative product. Some daily-use porcelains integrate clay and water plasticity based on visible texture, enhancing the interactivity and fun. The exquisite size of Jun porcelain has become a hands-on appreciation and tea set. One can feel its charm. of creation and the natural changes of heaven and earth on this one-inch object. It has promoted the inheritance of Yuzhou Jun porcelain and the design of derivatives.

\section{ORIGINS OF YUZHOU JUN PORCELAIN AND ITS DAILY-USE PORCELAIN}

Some scholars believe that the Yuzhou Jun kiln "dates back to the Tang Dynasty", associated with the rapid development of ceramics at that time. At that time, the kilns in some areas of Henan Province were used to produce flower-glazed porcelains, which had black and brown glazes burnt by high temperatures, with various color spots. They were named as "Tang Jun" by ceramicists. Therefore, it is undeniable that the flowerglazed porcelain of the Tang Dynasty had a significant impact on the production of Jun porcelain. At the beginning of the firing of Jun porcelain, "the traditional Jun porcelain wares were featured with purple or red spots on the green glaze, which made them different from other celadons [2]." Other scholars have argued that "there is no relationship between flower-glazed porcelain and Jun porcelain in origin. Jun porcelain is originated as 
print celadon in the western region of Henan in the midto late Northern Song Dynasty [3]." "Tang dynasty flower-glazed porcelain had a direct influence on the decorative techniques of Jun porcelain, but it has nothing essential in common with Jun porcelain [4]." "The general development of porcelain industry in the Northern Song Dynasty had produced a large amount of common daily-use porcelains, which were widely used by the people then. The porcelains produced in Kaifeng official kilns, Ruzhou Ru kiln, Yuzhou Jun kiln, and Dingzhou Ding kiln were the best-known [5]." It is obvious that the great achievement made by the Jun kilns is the creation of multi-colored glazes, and Yuzhou Jun porcelain was already appeared in the Song dynasty. It had formed a unique style in terms of both craftsmanship and aesthetics of shape.

According to the historical records and archaeological findings, the production of Song dynasty Jun porcelain was mostly for daily use. Its official kilns were rich and diverse in daily-use porcelains, which had simple, dignified and elegant shapes with dense body. The daily-use Jun porcelains made in Yuan Dynasty include bowls, jars, plates, pots, plates, bottles, incense burners, etc., The shape is balanced, and the decoration is simple. In Chenghua period in Ming Dynasty, porcelains were successfully modelled on the Northern Song copper-red glazed Jun porcelains. In the Qing Dynasty, small flowery vine vessels, round washing bowls, jars, bottles, flowery pots, bowls, plates and drum-like bowls, as well as porcelain stoves, wine goblets, washing bowls, peach-shaped figures, Buddha hands and other daily objects were also remade. It is worth noting that during this period of history, from the Ming Dynasty to the early and mid-Qing period, although the craft of Jun porcelain production was still being passed down in the folklore, the overall output for daily use was not only small, but also of poor quality. Therefore, the inheritance of Jun porcelain production techniques showed a decreasing trend. During the Republican period, the production of Jun porcelain started to revive, and some family workshops explored the firing of "stove Jun porcelain" and some traditional kiln-transmuted wine goblets. They had opened new possibilities for the recovery of Jun porcelain, and had also contributed to the inheritance of modern Jun porcelain and its mass production for daily use.

\section{DOMINANT TEXTURE BETWEEN CONCAVE AND CONVEX}

Texture generally refers to the textural structure of an object's surface, or the variation of texture after processing. In this article, the "texture beauty" of dailyuse Jun porcelain emphasizes its visual and tactile sensation of the surface texture. It is a surface texture formed by manually and intentionally using a mixture of clay and water after firing. The texture beauty of Jun porcelain cannot be separated from the richness of the mixture of clay and water. It will have different conditions with the level of moisture. The slurry clay is suitable for the mold, and through the process of slurry injection and drying, it can produce the same size of plain base. On the other hand, the wet clay can keep its moist surface in the humid environment for the production of hand-pulled base. The combination of clay and water itself has a natural tactile texture feeling. Moreover, porcelain craftsmen would interestingly carve, knead, squeeze, press, mold, carve, underglaze, glaze etc., through which the porcelain will form different styles and different functions of the texture effect. As for the fabricated texture, the plasticity, thixotropy and bonding of the clay as well the expressibility of the glaze directly record the craftsmen's feeling of formal skill and life experience [6].

\subsection{The initial birth of the embryo}

The raw materials used for Jun porcelain are quartzite and kaolin clay, and the clay comes from the natural resources. The quartzite and kaolin are polished by a churning machine into a fine raw material that is mixed with water to become the mud, which is used to fill the mold. The mold to be injected with the mud is turnover mold. After being injected two to three times, open the mold to allow the parts to dry naturally until the water inside fully evaporates. The hand-pulling process relies on the movement and experience of hand skills, which is up to 19 steps, which are: clay block holding, small fork, large fork, line cutting, plating, Liaohuan, Xuanhuan, Xuandi, Mohuan, Kenghuan, ornament design, ornament making, ornament drying, ornament gluing, firing with honey, plain firing, kiln outing, picking and selecting, and water gluing [7]. Generally, when gradually form the shape of a daily-use porcelain, the object is separated from the clay by a thin thread for drying or gluing ofornaments. The first $700^{\circ}$ firing can be done when the ornament body becomes "grayish white", so porcelains can be glazed when it is of good quality with no defects.

\subsection{Base texture}

The formation of the dominant texture is decorated on the surface of porcelain with the help of some tools manually. As early as the Song Dynasty, ceramics with patterns had already become popular, and porcelain carving methods are different due to its characteristics. For example, the Ding kiln carving is deeper, the Zhang Longquan kiln is shallower with categorial differences[8]. Different tools leave different types of patterns due to their unique characteristics and ways, and carving knives and even needles can be used for pattern carving, and the final pattern is still formed by the accumulated experience of the craftsman, through the manual shaping of the final formation of different dominant texture. 
When we researched and studied at the kilns of the Haojun Workshop in Shenlong Town, we saw that most of the daily-use porcelain is made with a smooth or frosted surface texture. For example, some workshops use threads to cut out the size of clay needed for beating, and then place it on a turntable for creation. Use both hands to pull clay block upward, and use the thumb to slowly flattens the lump, and tilt it from the center outward. The tea set then gradually reveals its shape. After that, both hands will be used to control the size of the cup mouth. At this point, the inner wall is still thicker, and it is still necessary to use both hands to control its thinness, or use a sponge to handle the cup mouth. After the shape is fine, the wares will be cut off with a thread for drying(Figure 1).

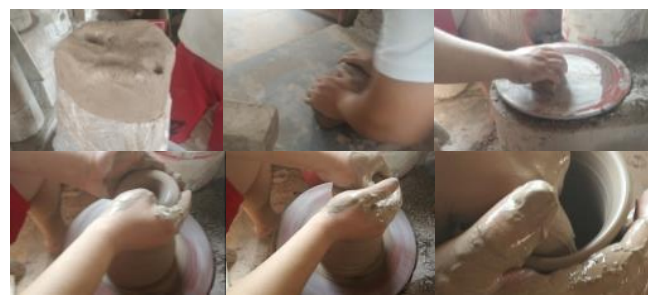

Figure 1 The process of hand throwing

In addition, the rare handmade jump-knife porcelain cups are a kind of base texture with a distinctive concave and convex surface. The surface of the cup is made by the light or slow force of the manual technique when the first base forms to create the yin and yang grooves, and intentionally arranged in orderly lines to form the tactile sensation of concavity and convexity. It can be maintained by the protective glaze with the variation of yin and yang when touched. This change is an orderly generation, a tactile and visual sensation brought about by the curve.

\section{THE RECESSIVE TEXTURE OF DISORDER AND RANDOMNESS}

\subsection{Kiln Transformation of Jun Kiln}

The production of daily-use Jun porcelain is subject to objective conditions of temperature, atmosphere, and glaze. Even if the same glaze is applied to the same dailyuse porcelain, the final visual differences in texture structure and color are obviously distinct. This is mainly because a small difference in one link can cause huge difference in the end. "The core of Jun kiln is the kiln transmutation, the copper glaze. Even if the same piece is put into the kiln, the firing results in a different outcome. This is what we often hear, 'one kiln is one kingdom for Jun porcelain' [9]. When firing in kilns, the surface glaze will have rich and brilliant colors due to temperature and other factors, under the high temperature oxidation reduction.

Jun kiln porcelain often transmutes in kilns. Besides the original color glaze, it will also have other colors. Its color change is the result of natural formation, the glaze beauty of abstract texture of color change under nonmanipulated state. The glaze color has natural beauty of smoothness, forming dodder marks. These heavy and deep changes in the magic of Jun porcelain texture provide with viewers and users an endless enjoyment of the beauty of the meaning.

\subsection{The five colors of Jun porcelain}

Daily-use porcelain is glazed after the base is initially fired and before the second firing. The role of this glaze is not only to protect the stability of the structure, but also to provide a decorative texture effect. For example, the classic copper-red glaze is formed by copper as oxide in a reducing atmosphere, as well as the liquid phase separation during the firing process. So it can scatter sky blue light, making the glaze blue milky light. "Five colors are complicated with infinite changes. It is fine but also seems to have a system. Generally known as five colors, blue, yellow, red, white, black. The recurrence of transmigration stretches to the unknown ...... Black is color that is the most difficult to change, and white also has several kinds[10]." The red color of Jun porcelain alone (purplish red) are more than a hundred kinds, such as the classic purple, the grape purple glaze and eggplant purple glaze. These two are also separated because of two different kinds of shades. Based on the five basic color system, the Jun porcelain can create a gorgeous, flowing and other charming colors, due to the hazy effect, drape, intermingling, transition on the glaze surface, which can make people have imagery and interactive feelings(Figure 2).

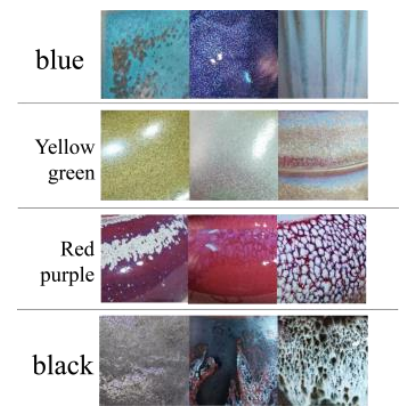

Figure 2 Color system of Jun Porcelain

Based on the glaze color and luster as well as the painted pattern, viewers get feel the sense of beauty, thus directly or indirectly affect their thoughts, emotions and attitudes. The hazy and sequential beauty reflected by ceramic texture is adopted in production, so that the visual impact is enhanced and sublimated into art [11]. The creator gives the daily-use Jun porcelain texture beauty. No matter it is the surface texture treatment of the base, or glaze surface texture treatment, they necessarily utilize the functions of colors, textures, etc. 


\subsection{The Rhythm of Jun}

Tempo, rhyme, symmetry, consistency, uniformity, balance, contrast, harmony, and other formal patterns have been found on primitive painted pottery since antient times. This has contributed to the brilliant ceramic art of China. The visual texture beauty produced by the natural kiln transformation of daily-use Jun porcelain is obviously inseparable from its influence, especially the pattern and the texture after glazing. Among the textures formed in Jun porcelain as a result of the physical and chemical changes that occurred after repeated glazing, some famous ones are the caviar pattern, earthworm walking pattern, dodder pattern, crab claw pattern, turtle back pattern, phoenix tail pattern, and Jinhua pattern, among which the earthworm walking pattern is a classic representative of Jun porcelain in Song dynasty [12]. This is exactly the natural variation that occurs in the kiln, and only at the moment of opening the kiln can one truly experience the color and texture brought about by its recessive texture (natural texture). That is, to experience the haloing in gradual change and to feel the beauty of daily-use Jun porcelain tea sets in similarity.

The texture of daily-use porcelain has an introverted and subtle oriental aesthetic, and it becomes a medium for the expression of the subject's aesthetic sense. It can transform into the illusion of consciousness into a tangible expression and becoming an essential element in the construction of the subject of creation [13]. The aesthetic beauty of daily-use porcelain is constantly being updated with the aesthetic experience of the times, and is more closely aligned with modern aesthetic demands with rich oriental elements. Jun porcelain in the new era is an aesthetic art that requires involvement of more designers. It needs broadly absorbing and learning from the merits of other ceramic arts to enrich and develop the art of Jun porcelain, including the exploration of the development and design of other derivatives.

\section{THE APPLICATION OF THE BEAUTY OF THE TEXTURE OF DAILY-USE PORCELAIN IN THE DESIGN OF DERIVATIVES}

\subsection{Fashionability of derivatives and daily-use Jun porcelain}

In recent years, many museums and tourism spots in China have introduced some art derivative products to the market, which has triggered the design field to have a thought on the design of cultural and creative products. Among them, the Forbidden City Museum as a popular IP has brought the development of cultural and creative products to a climax. For example, the Forbidden City tape, Big Year bracelet, the Forbidden City cat, the ice cream of ridge animal and other products combined with the traditional cultural elements of the Forbidden City. There is Buddha eye mask from the Dunhuang Museum's, Silk Road hand letter, Dunhuang skateboard, Dunhuang luggage tag, etc. Many provincial museums and tourist attractions have developed derivative designs, which not only promotes excellent local culture but also drives the development of the regional economy.

As the social economy develops rapidly and the consumers' material living standards improves gradually, the aesthetic demand for spiritual culture and consumption has been increasing constantly. People's aesthetic demand for porcelain is increasingly becoming more for middle-class and they also personalized their aesthetic demands. Because of the market competition, some porcelains have brought people a rich aesthetic experience by the change of glaze color (i.e., the texture beauty of glaze colors). Due to the effect of phosphoric acid in the glaze, the surface of Jun porcelain is quite milky, revealing brown eyes and bubbles. It can have an effect of transparency loss, making the glaze color not only splendid and magnificent, but also jade-like, subtle and explicit [14]. The form of a cat is refined and then is turned into a mass-produced products. After firing at high temperatures, each cat has a different color due to the different glazes applied. Meanwhile, for some fashionable Jun porcelain works, through intentional scoring, extrusion, mold printing, carving, glazing and other processes, their shape of the color base fired by its glaze will also have different texture beauty. In the era of pursuing personalized consumption, such uniqueness can reflect individual character, temperament, and taste, and therefore better achieve the demand for a personalized view of consumption and aesthetics.

\subsection{Jun porcelain derivatives and design development}

Currently, many stores have opened in Shenlong Town, Yuzhou, and are mainly selling decorative porcelains and daily-use porcelains. Although there are also shelves for showing small objects on the street, such as porcelain whistles and cartoon ornaments, design works of Jun porcelain derivatives are few. In the context of today's Jun porcelain-driven tourism consumption in Yuzhou, the demand for traditional daily-use porcelain is significantly declined 'because consumers' aesthetic needs are more thirst for diversified, humane, and culturally rich products. Also since the functionality and quality of daily-use ceramics have reached a certain standard stage due to the development of technology, designers are paying more and more attention to the market role. They will pay attention to the aesthetic needs of consumers, changing from the 'form after function' to 'form after demand'. They began to fulfill the aesthetic needs of higher levels [15]."In the context of "Internet+", the invention of digital new media technology has given 
rise to a communication medium for design and redesign. Integrated with the increasingly sophisticated AI technology, it is possible for people to learn the detailed process of hand-pulling and production techniques at home. Or the texture and rhythm of Jun porcelain can be displayed in a three-dimensional and dynamic way. The imperceptible beauty of the tea set in the hightemperature kiln transformation can be shown through a combination of visual and auditory sense. This can also amply and reproduce the unique opening pattern of ceramics. With the interface design of the mobile app, integrate the beauty of the imagery and the emotional experience of Jun porcelain, making it functional and rich in vision. By taking advantage of new media technology, the intangible cultural heritage resources of Jun porcelain can be better integrated and its beauty of the unique oriental craftsmanship can be promoted in today's modern era.

Today, some masters or makers of Jun porcelain have developed derivatives of Jun porcelain in line with market needs. For example, the derivative Jun porcelain animal shapes are based on the realization of the texture structure through the clay animal shapes and the chemical reaction of the glaze during the firing process. 。 The derivative teapots, porcelain vases, pipas, and pumpkins are not only novel and unique for their clay base, but also well utilized of the texture effect on the porcelain surface formed by the glaze during the firing process. This has increased their aesthetic and exquisite high-grade quality. What is more, as the modeling and decoration of artifact, the derivative Jun porcelain zen plate and jewelry cleverly use the variations in texture to colorfully decorate the main pattern. Especially for the Jun porcelain jewelry, after determining the framework and tone of the work, the Jun porcelain texture pieces are inlaid into the bracelet, like gemstone decorations, which further enhance and beautify the pieces.

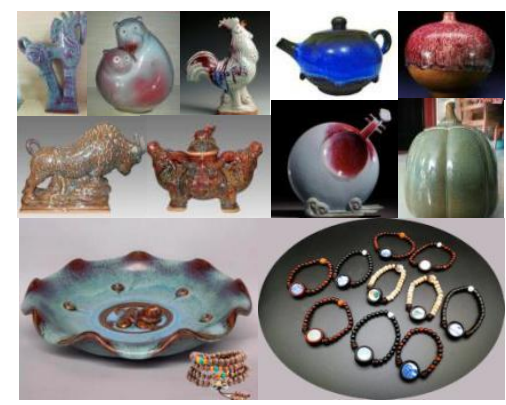

Figure 3 Jun porcelain derivatives

\section{CONCLUSION}

As a material carrier of the spirit of Jun porcelain techniques, based on the current market, directly reproduce the shape and texture of traditional daily-use Jun porcelain are still not too many. On the other hand, derivatives that borrow shapes and textures from other daily ceramics account for a relatively large share. The design of daily-use Jun porcelain derivatives should be based on market demand as well as the aesthetic needs of consumers, and should be considered in terms of shape, decoration, color, texture, and emotion to guide the aesthetic psychology of modern consumers. Therefore, it can increase its strength in the competition of homogenized daily-use Jun porcelain, and also realize new vitality and vigor of daily-use Jun porcelain based on the traditional Jun porcelain art. Today, Yuzhou dailyuse porcelain gradually develops into a variety of forms. Its surface textures are natural and is also the result of exploration for context after natural simulations. While placing more emphasis on the creator's intention and enhancing the interest in works, the visual beauty of the texture surface and its presentation have enhanced the aesthetic appeal of daily-use porcelain. This make it more beautiful and collectible in a practical sense. The integration of the texture beauty of daily-use porcelain into the design of derivatives will help preserve and pass on the skills of Jun porcelain, and allow more people to understand and appreciate the important role that Jun porcelain once played in history as a ceremonial vessel.

\section{REFERENCES}

[1] Xu Zhiheng. Yinliuzhai porcelain talks [M]. Zhonghua Book Company, 2001:40

[2] Yan Fuli. 18 lectures on Jun porcelain [M]. Beijing: Chinese publishing house, 2009:6

[3] Li Minju. Several concepts of Jun porcelain [J]. Journal of the National Palace Museum, 2017 (3): 31-36

[4] Xie Yihan. Study on the inheritance of Yuzhou Jun porcelain traditional production technology [D]. China Academy of art, 2014:15

[5] Cai Wenbiao et al. General history of China [M]. Beijing: People's publishing house, 1978:75

[6] Wang Fen, Liu Zijian. The causes of ceramic texture and its aesthetic artistic conception [J]. Decoration, 2017 (10): 122

[7] Xie Yihan. Research on the inheritance of Yuzhou Jun porcelain traditional production technology [D]. China Academy of art, 2014.49-50

[8] Xu Zhiheng. The talks of Yinliuzhai porcelain kiln [J]. Art, 2020 (3): 118-119

[9] Li Jiang, Tang Yedong. Travelling by objects and rebirth - Inheritance and innovation of Jun kiln Jun porcelain by Ren Yingge and Liu Hongsheng [J]. Decoration, 2019 (3): 32-35

[10] Xu Zhiheng. The talks of Yinliuzhai porcelain kiln [J]. Art, 2020 (3): 92-93 
[11] Zhang Lisha. Systematic study on wood carving materials for craft display [D]. Nanjing: Nanjing Forestry University, 2015

[12] Wang Qingbin. Artistic characteristics and design of Jun porcelain in Song Dynasty [J]. National art, 2010 (3): $80-82$

[13] Li Yunfeng. Aesthetics and aesthetic culture from the perspective of daily ceramics [J]. Ceramic research, 2019 (1): 52-54

[14] Xu Wen, Lv Pintian. Traditional handicrafts [M]. Hefei: Huangshan publishing house, 2015:31

[15] Shen Jie. Research on daily ceramic design based on the aesthetic needs of young consumers [J]. China ceramics, 2017 (9): 88-92 